\title{
Pre-exposure prophylaxis for sexually-acquired HIV risk management: a review
}

This article was published in the following Dove Press journal:

HIVIAIDS - Research and Palliative Care

28 April 2015

Number of times this article has been viewed

\author{
James Wilton' \\ Heather Senn² \\ Malika Sharma ${ }^{3}$ \\ Darrell HS Tan ${ }^{4,5}$ \\ 'Canadian AIDS Treatment \\ Information Exchange (CATIE), \\ ${ }^{2}$ Department of Family and \\ Community Medicine, University \\ of Toronto, ${ }^{3}$ Wilson Centre for \\ Research in Education, University \\ Health Network, University of \\ Toronto, ${ }^{4}$ Division of Infectious \\ Diseases, St Michael's Hospital, \\ ${ }^{5}$ Department of Medicine, University \\ of Toronto, Toronto, ON, Canada
}

Correspondence: Darrell HS Tan Division of Infectious Diseases, St Michael's Hospital, 30 Bond St, 4CC - Room 4-I79, Toronto, ON, M5B IW8 Canada

Tel +l 4168645568

Fax + I 4168645310

Email darrell.tan@gmail.com

\begin{abstract}
Despite significant efforts, the rate of new HIV infections worldwide remains unacceptably high, highlighting the need for new HIV prevention strategies. HIV pre-exposure prophylaxis (PrEP) is a new approach that involves the ongoing use of antiretroviral medications by HIV-negative individuals to reduce the risk of HIV infection. The use of daily tenofovir/ emtricitabine as oral PrEP was found to be effective in multiple placebo-controlled clinical trials and approved by the United States Food and Drug Administration. In addition, the Centers for Disease Control and Prevention in the United States and the World Health Organization have both released guidelines recommending the offer of oral PrEP to high-risk populations. The scale-up of PrEP is underway, but several implementation questions remain unanswered. Demonstration projects and open-label extensions of placebo-controlled trials are ongoing and hope to contribute to our understanding of PrEP use and delivery outside the randomized controlled trial setting. Evidence is beginning to emerge from these open-label studies and will be critical for guiding PrEP scale-up. Outside of such studies, PrEP uptake has been slow and several client- and provider-related barriers are limiting uptake. Maximizing the public health impact of PrEP will require rollout to be combined with interventions to promote uptake, support adherence, and prevent increases in risk behavior. Additional PrEP strategies are currently under investigation in placebo-controlled clinical trials and may be available in the future.
\end{abstract}

Keywords: HIV prevention, biomedical intervention, tenofovir, emtricitabine

\section{Introduction}

Despite significant efforts, the rate of new HIV infections worldwide remains unacceptably high. According to the Joint United Nations Programme on HIV/AIDS (UNAIDS), there were an estimated 2.1 million new HIV infections in $2013^{1}$ and country-level surveillance suggests that HIV incidence is rising among certain populations, such as among men who have sex with men (MSM) in North America, Western Europe, and Australia, ${ }^{2}$ and people who inject drugs (PWID) in Central Asia. ${ }^{3}$ This continuing epidemic highlights the urgent need for new HIV prevention strategies.

HIV pre-exposure prophylaxis (PrEP) involves the ongoing use of antiretroviral medications by HIV-negative individuals to reduce the risk of HIV infection. This prevention approach was found to be effective in multiple randomized, placebo-controlled, double-blinded clinical trials (RCTs). Within the past 3 years, the United States Food and Drug Administration (FDA) has approved tenofovir (TDF) plus emtricitabine (FTC) for use as oral PrEP and the US Centers for Disease Control and Prevention (CDC) and the World Health Organization (WHO) have both released guidelines recommending the offer of oral PrEP to individuals at high risk of HIV infection. ${ }^{4,5}$ 
Open-label extensions (OLEs) of PrEP RCTs and demonstration projects are currently underway in several countries to evaluate "real-world" implementation issues. This paper discusses the current and future state of PrEP science and implementation.

\section{Interpreting RCT evidence on PrEP efficacy and safety}

\section{Efficacy}

Several RCTs have found that the use of a daily pill containing TDF alone, or in combination with FTC, can reduce the risk of HIV transmission in key populations, including heterosexual serodiscordant couples, sexually active heterosexual men and women, MSM, and PWID. ${ }^{6-11}$ While the RCT demonstrating effectiveness among MSM also included transgender women who have sex with men, they represented a minority $(1.2 \%)$ of participants enrolled. ${ }^{6}$

In these RCTs, the overall reduction in HIV risk provided by oral PrEP ranged from $0 \%-75 \%$ (Table 1). There is a general consensus that different levels of adherence among participants are responsible for this wide range in efficacy estimates. ${ }^{12}$ While adherence to daily pill-taking, according to self-report and pill counts, in all clinical trials was high (84\%-95\%), the proportion of participants in the PrEP arms with detectable serum drug levels was lower and ranged from $24 \%-82 \%$. In the two studies where the proportion with detectable drug levels was $30 \%$ or less, there was no statistically significant difference in HIV incidence between the PrEP and placebo arms. ${ }^{10,11}$ Both of these trials (FEM-PrEP ${ }^{10}$ and VOICE ${ }^{11}$ ) enrolled high-risk heterosexual women in sub-Saharan Africa, raising initial concerns that PrEP may not work for women. However, TDF-based oral PrEP was effective for women in the Partners PrEP and TDF2 studies. ${ }^{7,8}$ Factors other than adherence, such as mucosal inflammation or differential drug penetration in the female genital tract, may have partially contributed to the lack of efficacy in the FEM-PrEP and VOICE studies. ${ }^{12}$

PrEP efficacy was higher among participants who adhered more consistently to daily pill-taking, as determined by selfreport, pill counts, and drug levels. In two nested case-control analyses, the risk of HIV infection was between $86 \%-92 \%$ lower among those with detectable drug in their blood when compared to those without. ${ }^{6,13}$ Drug levels equivalent to taking TDF/FTC daily were associated with a $99 \%$ reduction in HIV risk in a pharmacokinetic-based modeling study. ${ }^{14}$ Interestingly, this pharmacokinetic model demonstrated a PrEP efficacy of $96 \%$ with four doses per week, suggesting intermittent strategies may be a viable option. Indeed, an RCT

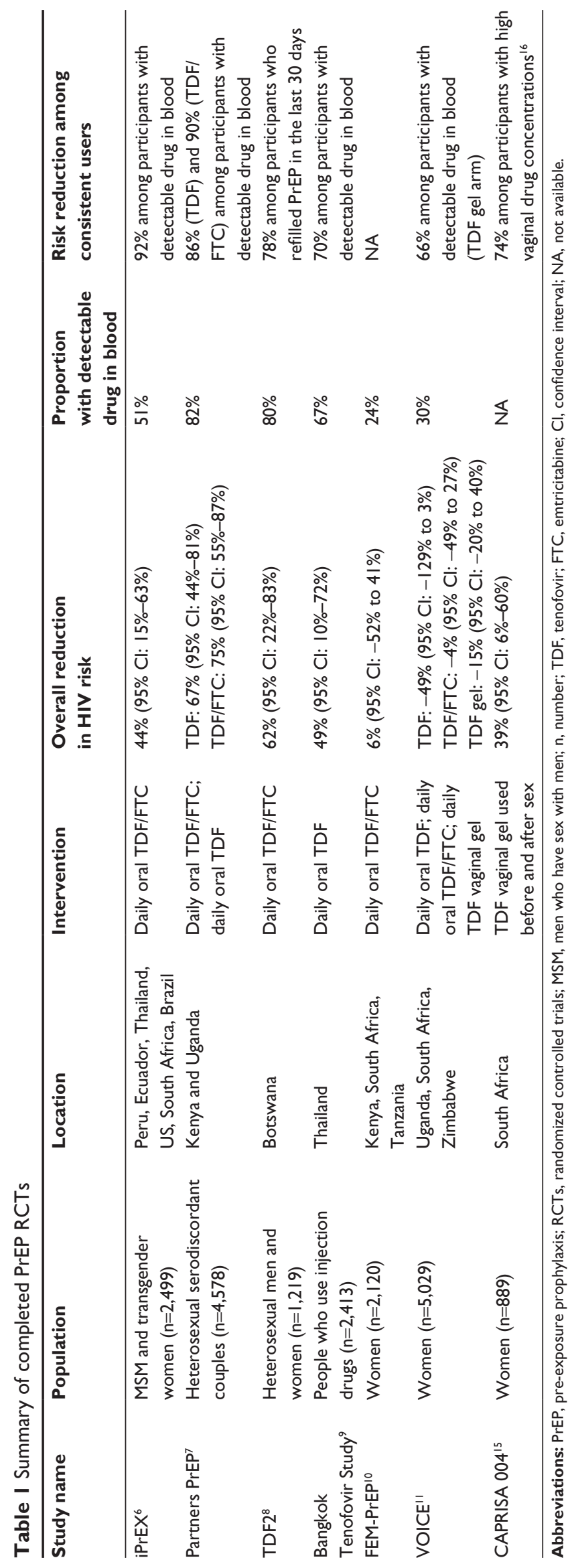


investigating intermittent TDF/FTC was recently stopped early due to high efficacy. ${ }^{15}$

Topical PrEP strategies have been evaluated in two clinical trials. In the CAPRISA 004 study, ${ }^{16}$ a TDF-based vaginal gel, applied before and after sex, reduced the overall risk of HIV infection among high-risk women in South Africa by $39 \%$. The reduction in HIV risk was 74\% among women who used the gel more consistently. ${ }^{17}$ The daily use of this TDF-based vaginal gel did not protect female study participants in the VOICE study, ${ }^{11}$ most likely due to low adherence.

\section{Safety}

TDF-based oral PrEP appears to be generally safe and well tolerated. This type of PrEP did not increase rates of serious (grade 3 or 4) adverse events in any studies. In some trials, oral PrEP did increase the risk of nausea, vomiting, diarrhea, unexplained weight loss, fatigue, and dizziness compared to placebo. ${ }^{6-11}$ However, side effects were generally mild, infrequent (affected 1\%-10\% of participants), and disappeared after 1 month or 2 months of use. Babies born to women who became pregnant while taking oral PrEP in the Partners PrEP study ${ }^{18}$ did not appear to have negative health outcomes. However, women discontinued PrEP when pregnancy was detected, which may have limited potential toxicity. The use of a TDF vaginal gel before and after sex was associated with a small increase in mild, self-limited diarrhea. ${ }^{16}$

PrEP has been associated with other, potentially more serious toxicities. TDF-based oral PrEP can cause small but statistically significant decreases in kidney ${ }^{19,20}$ and liver function ${ }^{9,10}$ and bone mineral density (BMD). ${ }^{21,22}$ Promisingly, renal function tended to return to normal after discontinuation of PrEP and decreases in BMD did not increase the risk of fracture. However, the long-term clinical significance of these changes remains unclear, as most trials only followed participants for a median of 1-2 years.

Development of drug resistance is a concern for individuals who use PrEP while unknowingly infected with HIV, because HIV treatment generally requires three antiretroviral drugs to fully suppress viremia. Fortunately, drug resistance was relatively rare among PrEP users who were HIV-negative at enrolment and became infected during follow up $(0 \%-12 \%$ of incident cases $) .^{6,8,12,23-25}$ However, resistance was frequently observed in participants who started PrEP when they were already infected (up to $100 \%$ of such cases). These individuals were likely in the acute stage of HIV infection at enrolment, as their infection was missed by antibody tests used at baseline to determine study eligibility. The high viral load during this stage may create optimal conditions for development of resistance. Promisingly, levels of drugresistant virus in those initiating PrEP during acute HIV infection in the iPrEX study ${ }^{25}$ decreased to low background levels 24 weeks after PrEP was discontinued. As such, the impact of PrEP-related drug resistance on future treatment options is unclear.

Importantly, clinical trials may have underestimated the rate of side effects, toxicities, and drug resistance due to low adherence among study participants. Furthermore, clinical trials had strict eligibility criteria and only enrolled generally healthy individuals. Therefore, the safety of PrEP when used by individuals with underlying health conditions is not known. What is evident, however, is the importance of baseline assessment and ongoing monitoring of HIV status, $\mathrm{BMD}$, renal and liver function, and pregnancy. Ruling out acute HIV infection prior to PrEP initiation is critical, by screening for acute HIV symptoms and by using testing technologies with shorter window periods, such as nucleic acid amplification tests and antigen/antibody combination tests.

\section{Translating PrEP into a reduction in HIV incidence in the "real world": challenges and opportunities}

Evidence of safety and reduced HIV risk at the individual level (ie, efficacy) from RCTs has led the WHO and CDC to recognize PrEP as an important component of a comprehensive approach to HIV prevention., ${ }^{4,5}$ PrEP scale-up is thus underway, but several implementation questions remain unanswered. For instance, the extent to which PrEP can contribute to reductions in HIV incidence outside of clinical trial settings (ie, effectiveness) is unknown. Modeling studies suggest that the public health impact of PrEP could be limited by slow uptake, poor adherence, and increases in risk behavior (risk compensation). ${ }^{26}$ To address these issues, more than 20 demonstration projects and OLEs of PrEP RCTs are currently planned or ongoing and will contribute to our understanding of PrEP use and delivery outside the RCT setting (Table 2).

\section{Uptake and hypothetical acceptability}

Overall, PrEP uptake among at-risk populations has been slow in the US, the country where the most progress has been made to move PrEP into practice. While surveys generally suggest that willingness to use PrEP among MSM (the population most affected by HIV in the US) is moderate to high, the proportion reporting PrEP use has not exceeded 
Table 2 Summary of planned and ongoing demonstration projects evaluating "open label" use of daily oral TDF/FTC

\begin{tabular}{lllll}
\hline Study details & Population(s) & Location(s) & Study design & Timeline \\
\hline The US & MSM ( $\mathrm{n}=600)$ & United States (San & PrEP offered to patients at two STD clinics and a & 20I2-20I5 \\
Demonstration & & Francisco, CA; Miami, & community health center. \\
Project, & & FL; Washington, DC) & \\
NCT0I632995 & & &
\end{tabular}

CRUSH

CRUSH,

NCT02183909

Young MSM of color aged United States

18-29 years $(n=670) \quad$ (Oakland, CA)

PATH-PrEP, $\quad$ MSM $(n=375)$

NCTOI781806

United States (Los

Angeles, CA)

\begin{tabular}{|c|c|c|}
\hline $\begin{array}{l}\text { CCTG 595, } \\
\text { NCT01761643 }\end{array}$ & MSM $(n=400)$ & $\begin{array}{l}\text { United States (Long } \\
\text { Beach, Los Angeles, } \\
\text { and San Diego, CA) }\end{array}$ \\
\hline $\begin{array}{l}\text { PrEPared and } \\
\text { Strong (P\&S), } \\
\text { NCT02167386 }\end{array}$ & Black MSM $(n=200)$ & $\begin{array}{l}\text { United States } \\
\text { (New York, NY) }\end{array}$ \\
\hline $\begin{array}{l}\text { PrEPare, } \\
\text { NCT0I632397 }\end{array}$ & MSM $(n=55)$ & $\begin{array}{l}\text { United States } \\
\text { (Boston, MA) }\end{array}$ \\
\hline
\end{tabular}

$\begin{array}{ll}\text { SPARK, } & \text { MSM }(\mathrm{n}=445) \\ \text { NCT02037594 } & \\ \text { Project PrEPare, } & \text { Young MSM aged } \\ \text { NCT0I772823 } & 15-17 \text { years }(\mathrm{n}=100) \text { and } \\ \text { and NCT0I769456 } & \text { I8-22 years }(\mathrm{n}=200)\end{array}$

HPTN 073,
NCT0I808352

SHIPP,

NCT0207489

MSM, IDU, heterosexual men and women $(n=I, 200)$

PrEPARATORY $-5, \quad$ MSM $(n=50)$ NCT02I 49888

\begin{tabular}{|c|c|}
\hline VicPrEPI05 & $\begin{array}{l}\text { MSM and heterosexual } \\
\text { men and women }(n=200)\end{array}$ \\
\hline PRELUDE, & MSM and heterosexual \\
\hline NCT02206555 & men and women $(n=400)$ \\
\hline $\begin{array}{l}\text { PROUD, } \\
\text { NCT02065986 }\end{array}$ & MSM $(n=500)$ \\
\hline $\begin{array}{l}\text { Benin Demo } \\
\text { Project, } \\
\text { NCT02237027 }\end{array}$ & $\begin{array}{l}\text { Female sex workers } \\
(n=250)\end{array}$ \\
\hline $\begin{array}{l}\text { PrEP-India, } \\
\text { NCT02। } 48094\end{array}$ & $\begin{array}{l}\text { Female and transgender } \\
\text { sex workers }(n=2,000)\end{array}$ \\
\hline $\begin{array}{l}\text { CHAMPS, } \\
\text { NCT02213328 }\end{array}$ & $\begin{array}{l}\text { Young heterosexual } \\
\text { men and women aged } \\
15-19 \text { years }(n=150)\end{array}$ \\
\hline $\begin{array}{l}\text { MP3-Youth, } \\
\text { NCTOI57II28 }\end{array}$ & $\begin{array}{l}\text { Young men and women } \\
\text { aged I5-24 years } \\
(n=I, 320)\end{array}$ \\
\hline
\end{tabular}

United States (New York, NY) United States

United States

(Los Angeles, CA;

Washington, DC;

Chapel Hill, NC)

United States

(Chicago, IL; Newark,

NJ; Philadelphia, PA;

Houston, TX)

Canada

(Toronto, ON)

Australia

(Melbourne, VIC)

Australia (New South

Wales)

United Kingdom

(London)

Benin (Cotonou)

India (Mysore,

Kolkata)

South Africa

Kenya (Kisumu,

Nairobi)
Evaluating a set of evidence-based interventions to address the sexual health of young MSM of color by enhancing activities at a youth clinic.

Evaluating the addition of PEP or PrEP to a CPP. Program stratifies participants into two cohorts based on risk:

I) high-risk cohort (CPP includes PrEP); 2) low/moderate-risk cohort (CPP includes PEP). Using an escalating-intensity adherence intervention based on real-time serum drug levels. Evaluating a text message-based adherence intervention (iTAB) using a controlled, randomized study design.

Evaluating an enhanced adherence intervention (peer navigators, text message reminders) using a controlled, randomized study design.

Evaluating adherence interventions using a two-arm, randomized study design (cognitive-behavioral-based adherence intervention versus health education with supportive counseling). Primarily a feasibility pilot randomized controlled trial.

A randomized, four-arm study evaluating interventions to enhance uptake and adherence.

Enrolling youth from Adolescent Medicine Trial Units. Comparing two risk-reduction interventions: I) Many Men, Many Voices (3MV); 2) personalized cognitive counseling. Assignment to intervention will occur at the site-level. Using a Client Centered Care Coordination (C4) model to deliver PrEP.

A health services implementation study at four federally qualified health centers. Measuring outcomes related to costs and clinical practice variation.

Evaluating an adherence intervention (using a before/after study design) administered through a local community-based organization. PrEP will be offered to 100 participants. Another 100 who decide to not take PrEP will also be followed. $-$

Participants will be randomized to I) start PrEP immediately, or 2) defer PrEP initiation for 12 months (note: deferred arm was discontinued in 2014 due to high effectiveness). Integrating treatment as prevention and PrEP into a combination prevention package. Plans to develop and evaluate an education adherence program. Comparing two approaches to PrEP delivery: I) peer educator home visits every other day; 2) weekly clinic pick-up. Plans to design and evaluate a risk assessment tool. Every 12 weeks, participants offered the following options: to continue PrEP, to stop PrEP but continue in the study, or to restart PrEP if previously stopped. Evaluating a sex-specific combination HIV prevention package for youth. Using a mobile delivery approach to PrEP provision. Only women are being offered PrEP.
2013-2017

2013-2017

2013-2015

2014-2017

2014-2015

2014-2018

2014-2016

2012-2016

2014-2016

2014-2016

2014-2016

2014-2016

(Continued) 
Table 2 (Continued)

\begin{tabular}{|c|c|c|c|c|}
\hline Study name & Population(s) & Location(s) & Study design & Timeline \\
\hline $\begin{array}{l}\text { Sibanye Health } \\
\text { Project, } \\
\text { NCT020430I5 }\end{array}$ & MSM $(n=200)$ & $\begin{array}{l}\text { South Africa } \\
\text { (Cape Town, Port } \\
\text { Elizabeth) }\end{array}$ & $\begin{array}{l}\text { Evaluating a combination package of biomedical, behavioral, } \\
\text { and community-level prevention interventions for MSM. }\end{array}$ & $2014-2015$ \\
\hline $\begin{array}{l}\text { PrEPBrasil, } \\
\text { NCT0I9896I I }\end{array}$ & MSM $(n=400)$ & $\begin{array}{l}\text { Brazil (Sao Paulo, } \\
\text { Rio de Janeiro) }\end{array}$ & - & $2014-2016$ \\
\hline $\begin{array}{l}\text { PARTNERS } \\
\text { demonstration } \\
\text { Project }^{104}\end{array}$ & $\begin{array}{l}\text { Serodiscordant } \\
\text { heterosexual couples } \\
(\mathrm{n}=1,000)\end{array}$ & Kenya, Uganda & $\begin{array}{l}\text { Evaluating delivery of treatment for prevention and PrEP. } \\
\text { PrEP offered as a "bridge" to ART use and is discontinued } \\
\text { once HIV-positive partner starts ART. }\end{array}$ & $2012-2015$ \\
\hline
\end{tabular}

Notes: Transgender women are eligible to participate in the majority of studies enrolling MSM. Unless otherwise specified, participants must be 18 years or older to meet eligibility criteria. Data from http://www.clinicaltrials.gov, http://vicprep.csrh.org ${ }^{105}$ and http://depts.washington.edu/uwicrc. ${ }^{104}$

Abbreviations: TDF, tenofovir; FTC, emtricitabine; MSM, men who have sex with men; $n$, number; PrEP, pre-exposure prophylaxis; STD, sexually transmitted disease; PEP, postexposure prophylaxis; CPP, customized prevention package; iTAB, individual Texting for Adherence Building; IDU, intravenous drug users; ART, antiretroviral therapy.

$5 \%$ in any of these early studies. ${ }^{27-32}$ Similar levels of hypothetical acceptability have been observed in MSM in other countries, ${ }^{27,28,33-35}$ as well as in sex workers, ${ }^{27,36}$ PWID, ${ }^{37}$ and women. ${ }^{38,39}$ However, populations other than MSM in the US remain understudied.

The most comprehensive study of PrEP uptake to date was based on prescription data from $55 \%$ of the retail pharmacies across the US; it determined that 3,253 individuals started PrEP between January 2012 and April 2014. ${ }^{40}$ While this study did not capture individuals accessing PrEP through demonstration projects or OLEs, the total number of PrEP users in the US at that time was undoubtedly much lower than the 500,000 that the CDC estimates would benefit from this strategy. ${ }^{41}$ The discordance between high hypothetical acceptability and low actual use suggest that barriers to PrEP uptake exist.

\section{Potential client-related barriers to uptake}

Uptake of PrEP can be initiated by a client or a provider, but several individual- and structural-level barriers may limit both. A major barrier to client-initiated PrEP (self-referral) is the lack of awareness among those at risk. ${ }^{27,28}$ Among individuals who are aware of PrEP and are interested in using it, a lack of access to a health care provider or a lack of comfort talking to a provider about PrEP may present additional barriers. ${ }^{30,32}$ In a recent survey of over 9,000 MSM in the US, $16 \%$ did not have a primary care provider (PCP), and only half of those with a provider felt comfortable talking to them about sex. ${ }^{32}$ Race-based medical distrust has been identified as a barrier to PrEP use among black MSM in the US. ${ }^{30}$

The high cost of PrEP is undoubtedly a major barrier to uptake worldwide, particularly in high-income countries where only branded TDF/FTC is available. In the US, financial coverage through private health insurance appears to be widespread, and Gilead Sciences has developed a financial assistance program for individuals without insurance. The extent of financial coverage in other countries is unclear.

\section{Potential provider-related barriers to uptake}

Provider-level barriers include a lack of PrEP awareness and knowledge, as well as negative opinions and attitudes toward PrEP. These barriers may deter service providers from recommending or prescribing PrEP to those who may benefit. Surveys of physicians in North America generally suggest that awareness, support, and willingness to prescribe are moderate to high. ${ }^{42-49}$ However, some surveys were biased by the high proportion of providers with experience working in HIV and, indeed, familiarity with HIV and PrEP has been associated with willingness to prescribe. ${ }^{43,48}$ Other potential barriers to prescribing include concerns about cost, safety, efficacy, risk compensation, adherence, time commitment, and a lack of guidelines. ${ }^{42-49}$

Confusion exists as to which health care providers are best suited to prescribe PrEP. While HIV specialists may have the most experience prescribing antiretrovirals, PCPs are more likely to have contact with uninfected, high-risk populations. ${ }^{50}$ In a Boston-based study, ${ }^{50} \mathrm{HIV}$ care providers indicated that PrEP delivery would be more feasible in primary care clinics. In another US study, willingness to prescribe PrEP among PCPs was between $20 \%-45 \%$, and this was associated with self-efficacy (ie, perceived ability to identify at-risk individuals, prescribe PrEP, and support PrEP users). ${ }^{46}$ This finding emphasizes the need for interventions to increase physician comfort and confidence in prescribing PrEP. Arguments have also been advanced to involve other health care providers in PrEP prescribing and monitoring, such as pharmacists and nurses, potentially increasing capacity and limiting costs. ${ }^{51}$

Nonprescribing service providers, such as staff at HIV testing sites and AIDS service organizations (ASOs), also 
have an important role to play in the implementation of PrEP. ${ }^{52}$ These organizations have regular contact with people at high risk of HIV infection and are in an ideal position to educate and link clients to locations where it is available. Similar to health care providers, a lack of awareness and negative PrEP attitudes among nonprescribing service providers may limit uptake. However, few studies have focused on these providers. In a Canadian survey of ASO staff, almost half (49\%) supported regulatory approval of PrEP, 26\% had been asked about PrEP, but the majority (61\%) felt that they did not have enough PrEP knowledge. ${ }^{53}$ More research is needed to understand the opinions of nonclinical providers and explore their role in PrEP implementation within the context of increasing medicalization of HIV prevention. ${ }^{54}$

\section{"Real-world" barriers to uptake and emerging data from demonstration projects and OLEs}

Few empirical studies have assessed "real-world" barriers to PrEP uptake. While client and provider education, PrEP referrals and linkage, and willingness to prescribe are important, one study found that they may not be sufficient to maximize uptake. ${ }^{55}$ In this study, "high risk" MSM presenting at HIV testing sites in San Diego, CA, USA from May 2012 to October 2012 were educated about PrEP and asked if they would consent to a referral to a clinic willing to prescribe PrEP at-cost. ${ }^{55}$ Referrals were offered to 416 men, but only 14 consented and even fewer (number $[n]=2$ ) started PrEP. The most common reasons for not consenting to referral were low perceived risk of HIV infection (30\%) and concerns about cost (48\%), long-term side effects (41\%), and taking daily medications (30\%). The two individuals who started PrEP covered the cost through their private health insurance.

Information emerging from demonstration projects and OLEs (where PrEP is offered free of charge by knowledgeable providers) suggests that uptake can be high in settings where cost and provider-related barriers have been removed. Settings explored in these open-label studies include a community health center, sexually transmitted disease (STD) clinics, and a private health organization in the US; ${ }^{56,57}$ reproductive health programs in high-income countries; ${ }^{56,58,59}$ genitourinary medicine clinics in the United Kingdom; ${ }^{60}$ prevention services for heterosexual serodiscordant couples in Eastern Africa $;{ }^{61}$ and the TDF2, iPrEX, and Partners PrEP OLEs. ${ }^{62-64}$ For example, the US Demonstration Project has integrated PrEP into STD clinics in San Francisco, CA, USA and Miami, FL, USA, and into a community health center in Washington,
DC, USA. ${ }^{56,57}$ From September 2012 to January 2014, 922 eligible MSM and transgender women were offered PrEP and $557(60 \%)$ initiated it. ${ }^{57}$ Of note, self-referrals $(n=299)$ and clinic referrals $(n=258)$ differed in terms of several sociodemographic characteristics, emphasizing the importance of promoting both in order to reach a wide range of at-risk individuals. The high acceptability in the OLEs is particularly reassuring as these individuals have already experienced several months of daily pill-taking and quarterly study visits. The most common client-related barriers to uptake among MSM in the iPrEX OLE and US Demonstration Project were low perceived risk of HIV infection, concerns about safety, and not wanting to take a pill every day. ${ }^{56,57,63}$

PrEP-related stigma has also emerged as a particularly concerning issue. In one demonstration project, the social harm most commonly reported by MSM was stigma from peers and health care providers as a result of their PrEP use. ${ }^{56}$ This stigma has also emerged in the media, with a Huffington Post article denouncing PrEP users as "Truvada Whores". ${ }^{65}$ Some PrEP users have reappropriated this term by posting images on social media sites of themselves wearing "\#TruvadaWhore" T-shirts (Figure 1). This sex-negative and judgmental reaction to PrEP draws parallels to the emergence of oral contraceptive pills in the 1960 s, which are now widely accepted. ${ }^{66}$

\section{Improving access and increasing uptake}

Increasing the awareness and knowledge of PrEP's proven efficacy and safety among at-risk populations and service providers will be an important first step to maximizing its appropriate uptake. Application of diffusion of innovation theory and lessons learned from the health communication field may be useful in designing interventions to increase

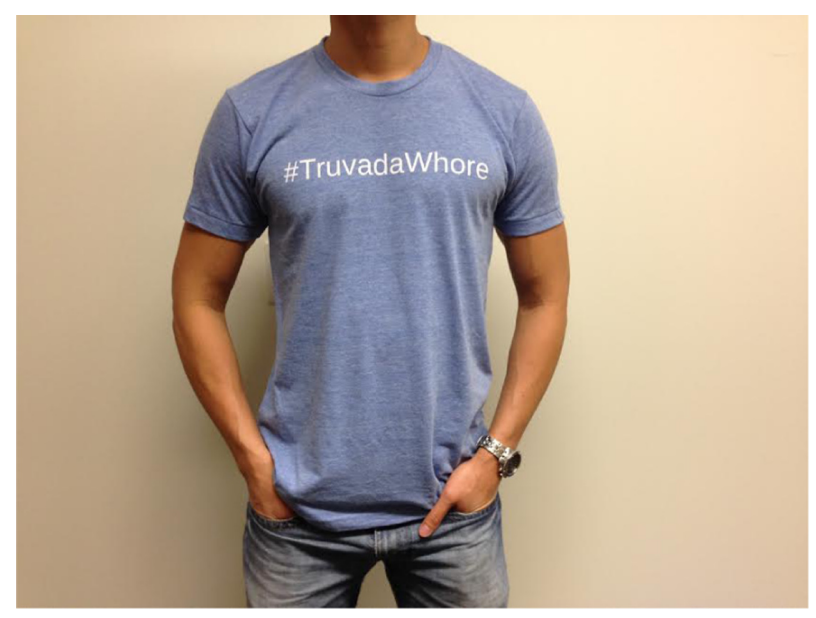

Figure I Truvadawhore T-shirt. 
uptake. ${ }^{67}$ Research is needed to understand how PrEP messaging affects uptake and how social and sexual networks can facilitate awareness and self-referrals for PrEP. ${ }^{68,69}$ Promoting PrEP as a healthy, responsible choice may help decrease stigma and increase uptake.

Other important interventions include those to bridge the disconnect between subjective and objective perceptions of HIV risk, ${ }^{70}$ empower individuals to self-advocate and self-refer, and facilitate financial coverage. In countries outside the US, regulatory approval and provider guidelines may help improve awareness, increase provider comfort in recommending/prescribing PrEP appropriately, and pave the way to wider financial coverage through public and private health insurance.

\section{Prioritizing PrEP uptake}

The public health impact of PrEP not only depends on how many people use it, but also who uses it. HIV risk within higher incidence populations is not uniform, and prioritizing PrEP uptake among those at highest risk is important to maximize its overall impact and cost-effectiveness. ${ }^{26}$ Promisingly, higher-risk sexual behaviors (as determined by self-report and the presence of sexually transmitted infections [STIs]) were associated with PrEP uptake among MSM in the iPrEX OLE. ${ }^{63}$

An important challenge is therefore finding ways to identify those individuals at highest risk. Service providers, particularly physicians, often have difficulty assessing HIV risk. ${ }^{71}$ For instance, surveys suggest that health care providers would prioritize serodiscordant couples for PrEP, ${ }^{46,49,72}$ but because treatment of the HIV-infected partner in such relationships is already associated with a $96 \%$ reduction in transmission risk, ${ }^{73}$ or perhaps more, ${ }^{74}$ PrEP may be of limited incremental value in this scenario. Indeed, research suggests most HIV transmissions originate from those who are unaware of their HIV status and a minority originate from those aware of their status, particularly if they are on treatment. ${ }^{75,76}$

Tools are needed to help providers identify those who may benefit most from PrEP. HIV risk criteria for determining PrEP eligibility in many guidelines and open-label studies are broad and nonspecific. ${ }^{77}$ Clinical HIV risk scoring tools may be useful to help screen individuals for PrEP eligibility and have been developed for MSM in the $\mathrm{US}^{78}$ and heterosexual serodiscordant couples in sub-Saharan Africa. ${ }^{79}$ Analyses of HIV risk factors in PrEP RCTs have also provided important insight into who should be prioritized for PrEP. A secondary analysis of the iPrEX trial found that the number needed to treat (NNT) was 62 overall and would be lowest if PrEP was targeted to MSM reporting cocaine use (NNT =12), an STI $(\mathrm{NNT}=41)$, or condomless receptive anal sex with unknown status partners $(\mathrm{NNT}=41)$, partners known to be HIV-positive (NNT $=24$ ), or only partners believed to be HIV-negative $(\mathrm{NNT}=15) .{ }^{80} \mathrm{~A}$ separate analysis identified syphilis as an important predictor of incident HIV infection in the iPrEX study.$^{81}$ These findings highlight the importance of providerinitiated discussions with clients on sexual behavior, partner HIV status, substance use, and STI history in order to assess PrEP eligibility.

\section{Adherence}

Adherence is critical to reduce HIV incidence among those who initiate PrEP. In PrEP RCTs, adherence was generally low and several factors were associated with poor compliance, such as substance use, a lack of partner support, longer time in study, ambivalence toward research, knowing the pill was investigational and may not work, stigma, low perceived risk of HIV infection, and lower-risk sexual activity. ${ }^{82-84}$ The most consistent factor associated with lower adherence across RCTs was younger age. ${ }^{82}$

Little information is available on PrEP adherence outside RCT settings, but some findings are beginning to emerge from demonstration projects and OLEs. These findings suggest adherence may be higher in open-label settings (where a person knows the pill they are taking is effective against HIV transmission), but it will likely remain a challenge for some individuals. In the $\mathrm{PrEX}$ OLE,${ }^{63}$ there was evidence that adherence was higher when compared to the RCT phase of the study, but overall adherence was low. Drug levels equivalent to $4-7$ pills a week were only present at $33 \%$ of study visits and most HIV infections occurred during gaps in PrEP use. Adherence was high at the beginning of the study, but it decreased over the 72-week follow up, suggesting the need for intensified interventions as time on PrEP increases. At week 4 in the US Demonstration Project, $77 \%$ of participants had drug concentrations consistent with taking at least four pills a week, but a smaller proportion (between 14\%-52\%, depending on the study site) were taking pills every day. ${ }^{57}$ Early discontinuation of the deferred arm in the PROUD demonstration project ${ }^{85}$ (due to high efficacy - $86 \%$ ) suggests that adherence in the PrEP arm was high. ${ }^{86}$

People at risk of HIV infection go through periods of higher and lower risk. ${ }^{87}$ Greater adherence during higher-risk periods is important to maximize the effectiveness of PrEP. Unfortunately, factors that put someone at higher risk may 
be the same that compromise adherence (eg, substance use, mental health issues). Promisingly, in the iPrEX OLE, higher drug concentrations were associated with self-reported HIV risk behaviors, such as condomless receptive anal sex, more sexual partners, having an HIV-positive sexual partner, and having a history of STIs. ${ }^{63}$ Use of drugs and alcohol were not associated with adherence. Ongoing HIV risk assessments of PrEP users may be important for informing uptake and intensifying adherence interventions during periods of higher risk.

PrEP rollout needs to be combined with interventions to support daily pill-taking and engagement in PrEP services. Currently, no evidence-based strategy is available to support open-label PrEP use, although several strategies were found to be effective/acceptable in other prevention fields ${ }^{88}$ and in PrEP RCTs. ${ }^{89-91}$ Ongoing and planned demonstration projects and OLEs are evaluating several types of approaches (Table 2).

\section{Risk behavior and risk compensation}

Increases in risk behavior as a result of PrEP use may offset the impact of this strategy on HIV incidence and increase the rates of other STIs. Similar to adherence, most information on risk compensation comes from RCTs. In these studies, self-reported risk behaviors declined, perhaps the result of ongoing risk-reduction services provided to participants. ${ }^{92-94}$ While social desirability bias may partly explain decreases in self-reported HIV risk behaviors, rates of HIV and syphilis infections (objective measures of risk behaviors) also decreased during follow up in the iPrEX RCT. ${ }^{92}$

Risk compensation may be more likely during openlabel use, where a PrEP user knows for certain that the pill he or she is taking is effective. However, the limited available evidence suggests this is not the case. In the Partners PrEP OLE, ${ }^{95}$ unprotected sex acts within the main partnership decreased when compared to the RCT phase, and rates of STIs and pregnancy did not increase. There was, however, a small increase in unprotected sex acts with outside partners. In the $\mathrm{iPrEX}$ OLE ${ }^{63}$ self-reported risk behaviors decreased over the duration of the study, and the incidence of syphilis was similar among those taking PrEP and those who were not. These findings suggest that risk compensation is not a concern when PrEP is used by people who are already engaging in higher-risk behaviors and when regular risk-reduction services are provided. Combining PrEP rollout with evidence-based HIV riskreduction approaches, ${ }^{96,97}$ as well as baseline/ongoing HIV risk assessments to determine PrEP eligibility, may limit the potential for risk compensation.

\section{Additional benefits of PrEP}

PrEP can provide benefits that go beyond its direct effect on HIV risk, as it offers an opportunity to engage high-risk individuals in services that they otherwise may not access. This includes services that are part of the standard PrEP package, such as regular HIV and STI testing, medical checkups, and risk-reduction services. These services can facilitate earlier identification of health conditions (eg, HIV and STIs) or vulnerabilities (eg, hepatitis B virus susceptibility) and provide an opportunity to (re)engage individuals in care, treatment, and prevention services. This may help improve health and prevent the secondary transmission of STIs and HIV. Interestingly, PrEP may also have a direct effect on STI incidence, as some research suggests that daily TDF/FTC reduces herpes simplex virus 2 and hepatitis B virus acquisition, ${ }^{98,99}$ as well as the occurrence of ulcers among those already infected with herpes simplex virus. ${ }^{100}$

PrEP also offers the opportunity to link high-risk individuals to other services to promote health and address an individual's underlying risk of HIV infection. Insight from postexposure prophylaxis (PEP) programs shows that MSM accessing this biomedical intervention tend to have a high prevalence of coexisting health problems, such as depression and substance use, which are "syndemic" and can reinforce HIV risk. ${ }^{101}$ Unfortunately, PEP access is rarely used to leverage additional services and, as a result, HIV risk often remains high after PEP is completed. ${ }^{102}$ Combining PEP and PrEP with routine screening for these health issues, and linkage to relevant services, will thus be important. Research also suggests that PrEP can have a positive and direct impact on mental health by decreasing some of the anxiety, guilt, and fear associated with "risky sex" and becoming infected with HIV. ${ }^{103}$

\section{The future state of PrEP}

While PrEP is currently synonymous with the use of daily TDF/FTC pills, this may not always be the case. Intermittent use of TDF/FTC has been found to be effective in the placebo-controlled IPERGAY trial. ${ }^{11}$ Further PrEP strategies under investigation include TDF-based vaginal and rectal gels, long-lasting rilpivirine injections, and slow-release dapivirine intravaginal rings. Many of these strategies have the potential to reduce costs, side effects, and barriers to adherence. 


\section{Conclusion}

PrEP is an exciting new addition to the armamentarium of biomedical and behavioral approaches to HIV prevention. However, important knowledge gaps remain and there has been limited open-label experience with PrEP. Data are beginning to emerge from demonstration projects and OLEs, and this information will be critical to guiding PrEP scale-up in different populations and geographic settings. As usage becomes more routine, close surveillance will be required to capture rare events and unintended consequences. Finally, as the toolkit of prevention strategies expands, there will be an increasing need for program science approaches evaluating PrEP as part of a broader suite of complex HIV prevention interventions.

\section{Disclosure}

DHST has received honoraria from Abbvie, Bristol Myers Squibb, Gilead, Janssen, Merck, and Viiv, and holds research grants from Gilead and Viiv. The other authors report no conflicts of interest in this work.

\section{References}

1. UNAIDS. The Gap Report. Geneva, Switzerland: UNAIDS; 2014. Available from: http://www.unaids.org/sites/default/files/media_asset/ UNAIDS_Gap_report_en.pdf. Accessed December 23, 2014

2. Beyrer C, Baral SD, van Griensven F, et al. Global epidemiology of HIV infection in men who have sex with men. Lancet. 2012;380(9839): 367-377.

3. El-Bassel N, Strathdee SA, El Sadr WM. HIV and people who use drugs in central Asia: confronting the perfect storm. Drug Alcohol Depend. 2013;132 Suppl 1:S2-S6.

4. US Public Health Service. Preexposure Prophylaxis for the Prevention of HIV Infection in the United States - 2014: A Clinical Practice Guideline. Atlanta, GA: Centers for Disease Control and Prevention; 2014. Available from: http://www.cdc.gov/hiv/pdf/prepguidelines2014. pdf. Accessed December 23, 2014.

5. World Health Organization. Consolidated Guidelines on HIV Prevention, Diagnosis, Treatment and Care for Key Populations. Geneva, Switzerland: World Health Organization; 2014. Available from: http:// apps.who.int/iris/bitstream/10665/128048/1/9789241507431_eng. pdf?ua=1\&ua=1. Accessed December 23, 2014.

6. Grant RM, Lama JR, Anderson PL, et al; iPrEx Study Team. Preexposure chemoprophylaxis for HIV prevention in men who have sex with men. N Engl J Med. 2010;363(27):2587-2599.

7. Baeten JM, Donnell D, Ndase P, et al; Partners PrEP Study Team. Antiretroviral prophylaxis for HIV prevention in heterosexual men and women. N Engl J Med. 2012;367(5):399-410.

8. Thigpen MC, Kebaabetswe PM, Paxton LA, et al; TDF2 Study Group. Antiretroviral preexposure prophylaxis for heterosexual HIV transmission in Botswana. N Engl J Med. 2012;367(5):423-434

9. Choopanya K, Martin M, Suntharasamai P, et al; Bangkok Tenofovir Study Group. Antiretroviral prophylaxis for HIV infection in injecting drug users in Bangkok, Thailand (the Bangkok Tenofovir Study): a randomised, double-blind, placebo-controlled phase 3 trial. Lancet. 2013;381(9883):2083-2090.

10. Van Damme L, Corneli A, Ahmed K, et al; FEM-PrEP Study Group Preexposure prophylaxis for HIV infection among African women. N Engl J Med. 2012;367(5):411-422.
11. Marrazzo JM, Ramjee G, Richardson BA, et al. Tenofovir-based preexposure prophylaxis for HIV infection among African women. New Engl J Med 2015;372(6):509-518.

12. van der Straten A, Van Damme L, Haberer JE, Bangsberg DR. Unraveling the divergent results of pre-exposure prophylaxis trials for HIV prevention. AIDS. 2012;26(7):F13-F19.

13. Donnell D, Baeten JM, Bumpus NN, et al. HIV protective efficacy and correlates of tenofovir blood concentrations in a clinical trial of PrEP for HIV prevention. J Acquir Immune Defic Syndr. 2014;66(3):340-348.

14. Anderson PL, Glidden DV, Liu A, et al; iPrEx Study Team. Emtricitabine-tenofovir concentrations and pre-exposure prophylaxis efficacy in men who have sex with men. Sci Transl Med. 2012;4(151): $151 \mathrm{ra} 125$.

15. Molina JM, Capitant C, Spire B, et al. On demand PrEP with oral TDF-FTC in MSM: Results of the ANRS Ipergay trial. Conference on Retroviruses and Opportunistic Infections; Feb 23-26, 2015; Seattle, WA. Abstract 23LB

16. Abdool Karim Q, Abdool Karim SS, Frohlich JA, et al; CAPRISA 004 Trial Group. Effectiveness and safety of tenofovir gel, an antiretroviral microbicide, for the prevention of HIV infection in women. Science. 2010;329(5996):1168-1174.

17. Karim SS, Kashuba AD, Werner L, Karim QA. Drug concentrations after topical and oral antiretroviral pre-exposure prophylaxis: implications for HIV prevention in women. Lancet. 2011;378(9787):279-281.

18. Mugo NR, Hong T, Celum C, et al; Partners PrEP Study Team. Pregnancy incidence and outcomes among women receiving preexposure prophylaxis for HIV prevention: a randomized clinical trial. JAMA. 2014;312(4):362-371.

19. Solomon MM, Lama JR, Glidden DV, et al; iPrEx Study Team. Changes in renal function associated with oral emtricitabine/tenofovir disoproxil fumarate use for HIV pre-exposure prophylaxis. AIDS. 2014;28(6):851-859.

20. Martin M, Vanichseni S, Suntharasamai P, et al; Bangkok Tenofovir Study Group. Renal function of participants in the Bangkok tenofovir study - Thailand, 2005-2012. Clin Infect Dis. 2014;59(5):716-724.

21. Liu AY, Vittinghoff E, Sellmeyer DE, et al. Bone mineral density in HIVnegative men participating in a tenofovir pre-exposure prophylaxis randomized clinical trial in San Francisco. PLoS One. 2011; 6(8):e23688.

22. Kasonde M, Niska RW, Rose C, et al. Bone mineral density changes among HIV-uninfected young adults in a randomised trial of preexposure prophylaxis with tenofovir-emtricitabine or placebo in Botswana. PLoS One. 2014;9(3):e90111.

23. Lehman DA, Baeten JM, McCoy C, et al. PrEP exposure and the risk of low-frequency drug resistance. Abstract presented at: 21 st Conference on Retroviruses and Opportunistic Infections; March 3-6, 2014; Boston, MA.

24. Parikh UM, Eskay KA, Hardesty RL, et al. HIV-1 resistance outcomes in seroconverters from MTN 003 (VOICE). Abstract presented at: 21st Conference on Retroviruses and Opportunistic Infections; March 3-6, 2014; Boston, MA.

25. Liegler T, Abdel-Mohsen M, Bentley LG, et al; iPrEx Study Team. HIV-1 drug resistance in the iPrEx preexposure prophylaxis trial. J Infect Dis. 2014;210(8):1217-1227.

26. Gomez GB, Borquez A, Case KK, Wheelock A, Vassall A, Hankins C. The cost and impact of scaling up pre-exposure prophylaxis for HIV prevention: a systematic review of cost-effectiveness modelling studies. PLoS Med. 2013;10(3):e1001401.

27. Young I, McDaid L. How acceptable are antiretrovirals for the prevention of sexually transmitted HIV?: A review of research on the acceptability of oral pre-exposure prophylaxis and treatment as prevention. AIDS Behav. 2014;18(2):195-216.

28. Holt M. HIV pre-exposure prophylaxis and treatment as prevention: a review of awareness and acceptability among men who have sex with men in the Asia-Pacific region of the Americas. Sex Health. 2014;11(2): 166-170.

29. Bauermeister JA, Meanley S, Pingel E, Soler JH, Harper GW. PrEP awareness and perceived barriers among single young men who have sex with men. Curr HIV Res. 2013;11(7):520-527. 
30. Eaton LA, Driffin DD, Smith H, Conway-Washington C, White D, Cherry C. Psychosocial factors related to willingness to use preexposure prophylaxis for HIV prevention among Black men who have sex with men attending a community event. Sex Health. 2014;11(3): 244-251.

31. Rucinski KB, Mensah NP, Sepkowitz KA, Cutler BH, Sweeney MM, Myers JE. Knowledge and use of pre-exposure prophylaxis among an online sample of young men who have sex with men in New York City. AIDS Behav. 2013;17(6):2180-2184.

32. Mayer KH, Oldenberg K, Novak D, Krakower D. Early adopters: correlates of chemoprophylaxis use in an online sample of US men who have sex with men. Abstract presented at: 21st Conference on Retroviruses and Opportunistic Infections; March 3-6, 2014; Boston, MA.

33. Leonardi M, Lee E, Tan DH. Awareness of, usage of and willingness to use HIV pre-exposure prophylaxis among men in downtown Toronto, Canada. Int J STD AIDS. 2011;22(12):738-741.

34. Young I, Li J, McDaid L. Awareness and willingness to use HIV preexposure prophylaxis amongst gay and bisexual men in Scotland: implications for biomedical HIV prevention. PLoS One. 2013;8(5): e64038.

35. Wheelock A, Eisingerich AB, Ananworanich J, et al. Are Thai MSM willing to take PrEP for HIV prevention? An analysis of attitudes, preferences and acceptance. PLoS One. 2013;8(1):e54288.

36. Ye L, Wei S, Zou Y, et al. HIV pre-exposure prophylaxis interest among female sex workers in Guangxi, China. PLoS One. 2014;9(1): e86200.

37. Stein M, Thurmond P, Bailey G. Willingness to use HIV preexposure prophylaxis among opiate users. AIDS Behav. 2014;18(9): 1694-1700.

38. Eisingerich AB, Wheelock A, Gomez GB, Garnett GP, Dybul MR, Piot PK. Attitudes and acceptance of oral and parenteral HIV preexposure prophylaxis among potential user groups: a multinational study. PLoS One. 2012;7(1):e28238.

39. Wingood GM, Dunkle K, Camp C, et al. Racial differences and correlates of potential adoption of preexposure prophylaxis: results of a national survey. J Acquir Immune Defic Syndr. 2013;63 Suppl 1: S95-S101.

40. Flash C, Landovitz R, Giler RM, et al. Two years of Truvada for preexposure prophylaxis utilization in the US. J Int AIDS Soc. 2014; 17(4 Suppl 3):19730.

41. Roehr B. FDA approves first drug to prevent HIV infection. BMJ. 2012;345:e4879.

42. White JM, Mimiaga MJ, Krakower DS, Mayer KH. Evolution of Massachusetts physician attitudes, knowledge, and experience regarding the use of antiretrovirals for HIV prevention. AIDS Patient Care STDS. 2012;26(7):395-405.

43. Sharma M, Wilton J, Senn H, Fowler S, Tan DH. Preparing for PrEP: perceptions and readiness of Canadian physicians for the implementation of HIV pre-exposure prophylaxis. PLoS One. 2014; 9(8):e105283.

44. Scherer ML, Douglas NC, Churnet BH, et al. Survey of HIV care providers on management of HIV serodiscordant couples - assessment of attitudes, knowledge, and practices. AIDS Care. 2014;26(11): 1435-1439

45. Karris MY, Beekmann SE, Mehta SR, Anderson CM, Polgreen PM. Are we prepped for preexposure prophylaxis (PrEP)? Provider opinions on the real-world use of PrEP in the United States and Canada. Clin Infect Dis. 2014;58(5):704-712

46. Sachdev DD, Stojanovski K, Liu AY, Buchbinder SP, Macalino GE. Intentions to prescribe preexposure prophylaxis are associated with self-efficacy and normative beliefs. Clin Infect Dis. 2014;58(12): 1786-1787.

47. Mimiaga MJ, White JM, Krakower DS, Biello KB, Mayer KH. Suboptimal awareness and comprehension of published preexposure prophylaxis efficacy results among physicians in Massachusetts. AIDS Care. 2014;26(6):684-693.
48. Tripathi A, Ogbuanu C, Monger M, Gibson JJ, Duffus WA. Preexposure prophylaxis for HIV infection: healthcare providers' knowledge, perception, and willingness to adopt future implementation in the southern US. South Med J. 2012;105(4):199-206.

49. Tellalian D, Maznavi K, Bredeek UF, Hardy WD. Pre-exposure prophylaxis (PrEP) for HIV infection: results of a survey of HIV healthcare providers evaluating their knowledge, attitudes, and prescribing practices. AIDS Patient Care STDS. 2013;27(10):553-559.

50. Krakower D, Ware N, Mitty JA, Maloney K, Mayer KH. HIV providers' perceived barriers and facilitators to implementing pre-exposure prophylaxis in care settings: a qualitative study. AIDS Behav. 2014;18(9): 1712-1721.

51. Bruno C, Saberi P. Pharmacists as providers of HIV pre-exposure prophylaxis. Int J Clin Pharm. 2012;34(6):803-806.

52. Hosek SG. HIV pre-exposure prophylaxis diffusion and implementation issues in nonclinical settings. Am J Prev Med. 2013;44(1 Suppl 2): S129-S132.

53. Senn H, Wilton J, Sharma M, Fowler S, Tan DH. Knowledge of and opinions on HIV preexposure prophylaxis among front-line service providers at Canadian AIDS service organizations. AIDS Res Hum Retroviruses. 2013;29(9):1183-1189.

54. Nguyen VK, Bajos N, Dubois-Arber F, O’Malley J, Pirkle CM. Remedicalizing an epidemic: from HIV treatment as prevention to HIV treatment is prevention. AIDS. 2011;25(3):291-293.

55. King HL, Keller SB, Giancola MA, et al. Pre-exposure prophylaxis accessibility research and evaluation (PrEPARE Study). AIDS Behav. 2014;18(9):1722-1725.

56. Liu A, Cohen S, Follansbee S, et al. Early experiences implementing pre-exposure prophylaxis (PrEP) for HIV prevention in San Francisco. PLoS Med. 2014;11(3):e1001613.

57. Cohen SE, Vittinghoff E, Anderson PL, Doblecki-Lewis S. Implementation of PrEP in STD Clinics and a Community Health Center: High Uptake and Drug Levels among MSM in the Demo Project. Abstract presented at: 21st Conference on Retroviruses and Opportunistic Infections; March 3-6, 2014; Boston, MA.

58. Whetham J, Taylor S, Charlwood L, et al. Pre-exposure prophylaxis for conception (PrEP-C) as a risk reduction strategy in HIV-positive men and HIV-negative women in the UK. AIDS Care. 2014;26(3): 332-336.

59. Vernazza PL, Graf I, Sonnenberg-Schwan U, Geit M, Meurer A. Preexposure prophylaxis and timed intercourse for HIV-discordant couples willing to conceive a child. AIDS. 2011;25(16):2005-2008.

60. Antonucci S, Desai M, Dolling D, et al. The UK PROUD PrEP pilot study: a baseline analysis. Abstract presented at: 20th International AIDS Conference; July 20-25, 2014; Melbourne, Australia.

61. Heffron R, Celum C, Mugo N, et al. High Initiation of PrEP and ART in a Demonstration Project among African HIV-discordant couples. Abstract presented at: 21st Conference on Retroviruses and Opportunistic Infections; March 3-6, 2014; Boston, MA.

62. Ndase P, Celum C, Campbell J, et al. Successful discontinuation of the placebo arm and provision of an effective HIV prevention product after a positive interim efficacy result: the partners PrEP study experience. J Acquir Immune Defic Syndr. 2014;66(2):206-212.

63. Grant RM, Anderson PL, McMahan V, et al; iPrEx study team. Uptake of pre-exposure prophylaxis, sexual practices, and HIV incidence in men and transgender women who have sex with men: a cohort study. Lancet Infect Dis. 2014;14(9):820-829.

64. Chirwa LI, Taylor A, Williams T, et al. Enrollment into open-label phase of TDF2 PrEP Study, Botswana, 2013. Abstract presented at: 20th International AIDS Conference; July 20-25, 2014; Melbourne, Australia.

65. Duran D. Truvada whores? The Huffington Post. December 11, 2012. Available from: http://www.huffingtonpost.com/david-duran/truvadawhores_b_2113588.html. Accessed September 15, 2014.

66. Myers JE, Sepkowitz KA. A pill for HIV prevention: déjà vu all over again? Clin Infect Dis. 2013;56(11):1604-1612. 
67. Vermund SH, Van Lith LM, Holtgrave D. Strategic roles for health communication in combination HIV prevention and care programs. J Acquir Immune Defic Syndr. 2014;66 Suppl 3:S237-S240.

68. Mustanski B, Ryan DT, Sanchez T, Sineath C, Macapagal K, Sullivan PS. Effects of messaging about multiple biomedical and behavioral HIV prevention methods on intentions to use among US MSM: results of an experimental messaging study. AIDS Behav. 2014;18(9): $1651-1660$.

69. Bacon O, Vittinghoff E, Cohen S, Doblecki-Lewis S. PrEP awareness in men who have sex with men (MSM) and transgender women (TGW) assessed for participation in the US PrEP demonstration project. Abstract presented at: 20th International AIDS Conference; July 20-25, 2014; Melbourne, Australia.

70. Gallagher T, Link L, Ramos M, Bottger E, Aberg J, Daskalakis D. Perception of HIV risk and candidacy for pre-exposure prophylaxis among men who have sex with men testing for HIV at commercial sex venues in New York City. LGBT Health. 2014;1(3): 218-224.

71. Krakower D, Mayer KH. Engaging healthcare providers to implement HIV pre-exposure prophylaxis. Curr Opin HIV AIDS. 2012;7(6): 593-599.

72. Arnold EA, Hazelton P, Lane T, et al. A qualitative study of provider thoughts on implementing pre-exposure prophylaxis (PrEP) in clinical settings to prevent HIV infection. PLoS One. 2012;7(7):e40603.

73. Cohen MS, Chen YQ, McCauley M, et al; HPTN 052 Study Team. Prevention of HIV-1 infection with early antiretroviral therapy. $N$ Engl J Med. 2011;365(6):493-505.

74. Rodger A, Bruun T, Cambiano V, et al. HIV transmission risk through condomless sex if HIV+ partner on suppressive ART: PARTNER study. Abstract presented at: 21st Conference on Retroviruses and Opportunistic Infections; March 3-6, 2014; Boston, MA.

75. Marks G, Crepaz N, Janssen RS. Estimating sexual transmission of HIV from persons aware and unaware that they are infected with the virus in the USA. AIDS. 2006;20(10):1447-1450.

76. Brown AE, Gill ON, Delpech VC. HIV treatment as prevention among men who have sex with men in the UK: is transmission controlled by universal access to HIV treatment and care? HIV Med. 2013;14(9): 563-570.

77. Zablotska I, Grulich A. Risk assessment and eligibility for pre-exposure prophylaxis to prevent HIV infection among men who have sex with men. Abstract presented at: 20th International AIDS Conference; July 20-25, 2014; Melbourne, Australia.

78. Smith DK, Pals SL, Herbst JH, Shinde S, Carey JW. Development of a clinical screening index predictive of incident HIV infection among men who have sex with men in the United States. J Acquir Immune Defic Syndr. 2012;60(4):421-427.

79. Kahle EM, Hughes JP, Lingappa JR, et al; Partners in Prevention HSVHIV Transmission Study and the Partners PrEP Study Teams. An empiric risk scoring tool for identifying high-risk heterosexual HIV-1serodiscordant couples for targeted HIV-1 prevention. J Acquir Immune Defic Syndr. 2013;62(3):339-347.

80. Buchbinder SP, Glidden DV, Liu AY, et al. HIV pre-exposure prophylaxis in men who have sex with men and transgender women: a secondary analysis of a phase 3 randomised controlled efficacy trial. Lancet Infect Dis. 2014;14(6):468-475.

81. Solomon MM, Mayer KH, Glidden DV, et al; iPrEx Study Team. Syphilis predicts HIV incidence among men and transgender women who have sex with men in a preexposure prophylaxis trial. Clin Infect Dis. 2014;59(7):1020-1026.

82. Amico KR, Stirratt MJ. Adherence to preexposure prophylaxis: current, emerging, and anticipated bases of evidence. Clin Infect Dis. 2014; 59 Suppl 1:S55-S60.

83. van der Straten A, Stadler J, Montgomery E, et al. Women's experiences with oral and vaginal pre-exposure prophylaxis: the VOICE-C qualitative study in Johannesburg, South Africa. PLoS One. 2014;9(2): e89118.
84. Haberer JE, Baeten JM, Campbell J, et al. Adherence to antiretroviral prophylaxis for HIV prevention: a substudy cohort within a clinical trial of serodiscordant couples in East Africa. PLoS Med. 2013;10(9): e1001511.

85. Medical Research Council Clinical Trials Unit. PROUD Study Interim Analysis Finds Pre-exposure Prophylaxis (PrEP) is Highly Protective against HIV for Gay Men and Other Men Who have Sex with Men in the UK. Wiltshire, UK: Medical Research Council, Clinical Trials Unit; 2014. Available from: http://www.proud.mrc.ac.uk/PDF/PROUD $\% 20$ Statement\%20161014.pdf. Accessed December 23, 2014.

86. McCormack S and Dunn D. Pragmatic Open-Label Randomised Trial of Preexposure Prophylaxis: The PROUD Study. Abstract presented at: 22nd Conference on Retroviruses and Opportunistic Infections (CROI); Feb 23-26, 2015; Seattle, USA.

87. Pines HA, Gorbach PM, Weiss RE, et al. Sexual risk trajectories among MSM in the United States: implications for pre-exposure prophylaxis delivery. J Acquir Immune Defic Syndr. 2014;65(5): 579-586.

88. Marcus JL, Buisker T, Horvath T, et al. Helping our patients take HIV pre-exposure prophylaxis (PrEP): a systematic review of adherence interventions. HIV Med. 2014;15(7):385-395.

89. Psaros C, Haberer JE, Katabira E, et al. An intervention to support HIV preexposure prophylaxis adherence in HIV-serodiscordant couples in Uganda. J Acquir Immune Defic Syndr. 2014;66(5): 522-529.

90. R Amico K, McMahan V, Goicochea P, et al. Supporting study product use and accuracy in self-report in the iPrEx study: next step counseling and neutral assessment. AIDS Behav. 2012;16(5):1243-1259.

91. Mansoor LE, Karim QA, Werner L, et al. Impact of an adherence intervention on the effectiveness of tenofovir gel in the CAPRISA 004 trial. AIDS Behav. 2014;18(5):841-848.

92. Marcus JL, Glidden DV, Mayer KH, et al. No evidence of sexual risk compensation in the iPrEx trial of daily oral HIV preexposure prophylaxis. PLoS One. 2013;8(12):e81997.

93. Martin M, Vanichseni S, Suntharasamai P, et al; Bangkok Tenofovir Study Group. Risk behaviors and risk factors for HIV infection among participants in the Bangkok tenofovir study, an HIV pre-exposure prophylaxis trial among people who inject drugs. PLoS One. 2014;9(3): e92809.

94. Liu AY, Vittinghoff E, Chillag K, et al. Sexual risk behavior among HIV-uninfected men who have sex with men participating in a tenofovir preexposure prophylaxis randomized trial in the United States. J Acquir Immune Defic Syndr. 2013;64(1):87-94.

95. Mugwanya KK, Donnell D, Celum C, et al; Partners PrEP Study Team. Sexual behaviour of heterosexual men and women receiving antiretroviral pre-exposure prophylaxis for HIV prevention: a longitudinal analysis. Lancet Infect Dis. 2013;13(12):1021-1028.

96. Eaton LA, Huedo-Medina TB, Kalichman SC, et al. Meta-analysis of single-session behavioral interventions to prevent sexually transmitted infections: implications for bundling prevention packages. Am J Public Health. 2012;102(11):e34-e44.

97. Johnson WD, Diaz RM, Flanders WD, et al. Behavioral interventions to reduce risk for sexual transmission of HIV among men who have sex with men. Cochrane Database Syst Rev. 2008;(3):CD001230.

98. Celum C, Morrow RA, Donnell D, et al; Partners PrEP Study Team. Daily oral tenofovir and emtricitabine-tenofovir preexposure prophylaxis reduces herpes simplex virus type 2 acquisition among heterosexual HIV-1-uninfected men and women: a subgroup analysis of a randomized trial. Ann Intern Med. 2014;161(1):11-19.

99. Heuft MM, Houba SM, van den Berk GE, et al. Protective effect of hepatitis $B$ virus-active antiretroviral therapy against primary hepatitis B virus infection. AIDS. 2014;28(7):999-1005.

100. Marcus JL, Glidden DV, McMahan V, et al. Daily oral emtricitabine/tenofovir preexposure prophylaxis and herpes simplex virus type 2 among men who have sex with men. PLoS One. 2014;9(3): e91513. 
101. Tan DH, Goddey-Erikefe B, Gough KA, Yoong D, Naccarato M, Hart T. High prevalence of syndemic health problems among patients using HIV post-exposure prophylaxis: implications for program delivery. Abstract presented at: 23rd Annual Canadian Association of HIV/ AIDS Research Conference; 23rd Annual Canadian Association of HIV/AIDS Research Conference; May 1-4, 2014; St John's, NL.

102. Poynten IM, Jin F, Mao L, et al. Nonoccupational postexposure prophylaxis, subsequent risk behaviour and HIV incidence in a cohort of Australian homosexual men. AIDS. 2009;23(9):1119-1126.

103. Koester K, Amico R, Liu A, et al. Sex on PrEP: qualitative findings from the iPrEx open label extension (OLE) in the US. Abstract presented at: 20th International AIDS Conference; July 20-25, 2014; Melbourne, Australia.
104. Partners Demonstration Project [webpage on the Internet]. University of Washington International Clinical Research Center; 2008. Available from: http://depts.washington.edu/uwicrc/research/studies/demo.html. Accessed December 23, 2014.

105. VicPrEP [homepage on the Internet]. Victorian Pre-Exposure Prophylaxis Project. Available from: http://vicprep.csrh.org/index.php. Accessed December 23, 2014.

\section{Publish your work in this journal}

HIV/AIDS - Research and Palliative Care is an international, peerreviewed open-access journal focusing on advances in research in HIV, its clinical progression and management options including antiviral treatment, palliative care and public healthcare policies to control viral spread. The journal welcomes original research, basic science, clinical \& epidemiological studies, reviews \& evaluations, expert opinion \& commentary, case reports \& extended reports. The manuscript management system is completely online and includes a very quick and fair peer-review system. Visit http://www.dovepress.com/ testimonials.php to read real quotes from published authors. 